\title{
Pelarutan Selektif Tembaga dari Limbah Printed Circuit Board dengan Hidrogen Peroksida
}

\author{
Gatut Ari Wardani $^{*}$, Rokiy Alfanaar ${ }^{\mathrm{b}}$, Sri Juari Santosa ${ }^{\mathrm{c}}$ \\ ${ }^{a}$ STIKes Bakti Tunas Husada Tasikmalaya, Jl. Cilolohan No. 36, Kota Tasikmalaya, Jawa Barat. 46115 \\ ${ }^{b}$ Program Studi Kimia, Fakultas Sains dan Teknologi, Universitas Ma Chung, Villa Puncak Tidar N-01, \\ Dau, Malang, Jawa Timur. 65151 \\ ${ }^{c}$ Jurusan Kimia, FMIPA, Universitas Gadjah Mada, Sekip Utara, Bulaksumur, Yogyakarta. 55281 \\ * Corresponding author \\ E-mail: gatutariwardani@stikes-bth.ac.id
}

DOI : 10.20961/alchemy.14.1.11168.51-59

Received 5 May 2017, Accepted 24 October 2017, Published online 1 March 2018

\begin{abstract}
ABSTRAK
Pelarutan selektif tembaga dari limbah printed circuit board (PCB) telah berhasil dilakukan. Logam tembaga yang terkandung di dalam papan PCB dapat dipisahkan menggunakan campuran hidrogen peroksida dan asam sulfat dengan variasi perbandingan volume $0: 1,1: 1,2: 1,3: 1,4: 1$, dan $5: 1$. Pemisahan optimal dilakukan dengan sistem perendaman selama 3 hari dengan campuran $\mathrm{H}_{2} \mathrm{O}_{2} / \mathrm{H}_{2} \mathrm{SO}_{4}=3: 1$ (v/v). Jumlah tembaga yang terkandung di dalam papan PCB dianalisis menggunakan $X$-ray fluorescense. Tembaga yang terkandung di dalam PCB sebesar 57,7\%. Pelarutan selektif dapat menurunkan kadar tembaga sehingga tembaga yang masih tersisa adalah sebesar 7,7 x $10^{-4} \%$. Penurunan kadar tembaga yang terkandung di dalam PCB mencapai 99,999\%. Analisis spektrometri serapan atom dilakukan untuk mengetahui jumlah tembaga yang terlarut yaitu sebesar $25,415 \mathrm{mg} / \mathrm{kg} \mathrm{PCB}$.
\end{abstract}

Kata kunci: limbah, pelarutan selektif, printed circuit board, tembaga

\begin{abstract}
Leaching of Copper from Printed Circuit Board Waste with Hydrogen Peroxide. Leaching of copper from printed circuit board (PCB) waste has been successfully performed. The copper metal contained in the PCB can be separated using a mixture of hydrogen peroxide and sulfuric acid with a variation of volume ratio is $0: 1,1: 1,2: 1,3: 1,4: 1$, and $5: 1$. Optimal separation is carried out by the immersion system for 3 days using $\mathrm{H}_{2} \mathrm{O}_{2} / \mathrm{H}_{2} \mathrm{SO}_{4}=3: 1(\mathrm{v} / \mathrm{v})$. The amount of copper contained in the PCB was analyzed using X-ray fluorescence. The copper contained in the printed circuit board is $57.7 \%$. The leaching process can decrease the copper content so that the remaining copper is $7.7 \times 10^{-4} \%$. The decrease of copper content contained in PCB reaches $99.999 \%$. Analysis of atomic absorption spectrometry was conducted to determine the amount of dissolved copper that is $25.415 \mathrm{mg} / \mathrm{kg}$ PCB.
\end{abstract}

Keywords: copper, leaching, printed circuit board waste 


\section{PENDAHULUAN}

Era modern seperti saat ini, kebutuhan barang-barang elektronik sangat tinggi. Barang-barang tersebut sudah menjadi kebutuhan primer bagi semua kalangan. Komputer atau gadget menjadi sesuatu yang paling diburu oleh semua kalangan. Hal ini menyebabkan sumbangan limbah elektronik ke lingkungan menjadi sangat tinggi karena setiap barang tersebut memiliki life time tertentu. Harga komputer atau gadget baru jauh lebih murah dibanding biaya perbaikan ketika mengalami kerusakan sehingga konsumen cenderung membeli yang baru dan membuang barang yang rusak ke lingkungan.

Secara umum, limbah peralatan elektronik dan listrik mengandung $40 \%$ logam diantaranya logam-logam berat. Sampah dari komputer-komputer bekas tersebut dapat merusak lingkungan sekitar, sehingga limbah dari komputer bekas harus dikelola dengan baik dan tepat. Salah satu upaya pengelolaan limbah adalah recovery logam dari komponen yang ada dalam komputer, khususnya PCB. Menurut Birloaga et al. (2013) kandungan terbesar dari suatu PCB adalah logam tembaga (30,57\%).

Tembaga merupakan konduktor panas dan listrik yang baik setelah emas. Kapasitas kalor tembaga pada $20{ }^{\circ} \mathrm{C}$ sebesar $24.440 \mathrm{~J} / \mathrm{mol} \mathrm{K}$. Tembaga juga merupakan unsur yang relatif tidak reaktif sehingga tahan terhadap korosi. Harga tembaga relatif lebih murah dibandingkan dengan emas. Alasan inilah yang mendasari penggunaan tembaga pada PCB. Pada umumnya, lapisan tembaga adalah lapisan dasar yang harus dilapisi dengan nikel atau krom.

Koyama et al. (2006) telah berhasil memisahkan tembaga dari limbah PCB dengan metode pelarutan selektif menggunakan larutan basa amoniak. Tembaga yang berhasil dipisahkan sebesar 82\% setelah pelarutan selektif selama 4 jam. Castro and Martins (2009) memisahkan tembaga dari limbah PCB dengan menggunakan pelarutan selektif serbuk PCB dalam larutan $\mathrm{H}_{2} \mathrm{SO}_{4} 2,18 \mathrm{~N}$ dan $\mathrm{HCl} 3 \mathrm{~N}$ yang berhasil memisahkan tembaga masing-masing sebesar $<0,01 \%$ dan 33,2\%. Tembaga juga dapat dipisahkan dengan

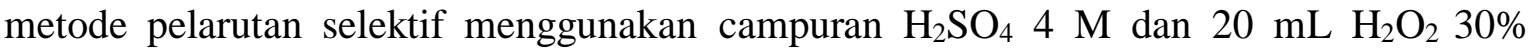
selama 3 jam dengan pengadukan $300 \mathrm{rpm}$ (Birloaga et al., 2013). Metode ini menghasilkan 90\% logam tembaga yang terpisah dari limbah PCB.

Menurut Adebayo et al. (2003), laju pengadukan pada proses pelarutan selektif menggunakan peroksida dapat menyebabkan terurainya hidrogen peroksida menjadi oksigen yang akan diserap oleh permukaan partikel sehingga dapat menghambat kontak antara partikel dengan peroksida. Oleh karena itu, pada penelitian ini digunakan proses pelarutan selektif menggunakan campuran asam sulfat dan hidrogen peroksida karena 
metode ini dapat menghasilkan persentase pelarutan selektif tembaga yang besar. Pelarutan selektif dilakukan tanpa pengadukan untuk mengurangi penguraian peroksida sehingga diharapkan menghasilkan lebih banyak tembaga. Temperatur optimal yang dapat digunakan untuk proses pelarutan selektif dengan menggunakan hidrogen peroksida sebagai oksidatornya adalah $30-50{ }^{\circ} \mathrm{C}$. PCB tidak dihaluskan dengan menggunakan gerinda karena putaran gerinda yang terlalu kencang dapat menyebabkan serbuk sampel banyak yang beterbangan (Wahib et al., 2014). Optimasi proses pelarutan selektif dilakukan sampai sebagian besar logam-logam non emas (tembaga) terlepas dari PCB meliputi parameter waktu $0,1,3$, dan 5 hari.

\section{METODE PENELITIAN}

Bahan-bahan yang digunakan dalam penelitian ini adalah limbah Printed Circuit Board (PCB) dari motherboard tipe Asus 2006 AMD Athlon x32 dan bahan-bahan dari Merck yang memiliki kualitas pure analysis di antaranya adalah: asam sulfat $\left(\mathrm{H}_{2} \mathrm{SO}_{4}\right)$, ammonium hidroksida $\left(\mathrm{NH}_{4} \mathrm{OH}\right)$, hidrogen peroksida $\left(\mathrm{H}_{2} \mathrm{O}_{2}\right)$, asam klorida $(\mathrm{HCl})$, dan akuades $\left(\mathrm{H}_{2} \mathrm{O}\right)$. Peralatan yang digunakan antara lain peralatan gelas laboratorium, neraca analitik (Ands GR-200), spektrometer fluorosensi sinar-X (XRF, Philips), spektrometer serapan atom (SSA, ContrAA 300),

\section{Penentuan kandungan logam dalam PCB}

PCB dari limbah CPU diambil dan dibersihkan dari komponen-komponennya seperti chipset, socket/CPU slots, BIOS chip, CMOS battery, memory slots, VGA slots, expansion slots, dan storage drive connector. Setelah bersih, kemudian dipotong-potong dengan ukuran sekitar $1 \mathrm{~cm}$ x $0,5 \mathrm{~cm}$. Kemudian kepingan PCB tersebut dikarakterisasi dengan menggunakan $X R F$ untuk menentukan kandungan logam didalamnya.

\section{Optimasi perbandingan $\mathrm{H}_{2} \mathrm{O}_{2} / \mathrm{H}_{2} \mathrm{SO}_{4}$ sebagai pelarut dalam pelarutan selektif tembaga}

Larutan $\mathrm{H}_{2} \mathrm{O}_{2} 30 \%$ (v/v) dicampur dengan $\mathrm{H}_{2} \mathrm{SO}_{4} 4 \mathrm{M}$ dalam gelas beker kemudian diaduk sampai homogen. Rasio $\mathrm{H}_{2} \mathrm{O}_{2} / \mathrm{H}_{2} \mathrm{SO}_{4}$ yang digunakan dalam penelitian ini yaitu 0 : $1 ; 1: 1 ; 2: 1 ; 3: 1 ; 4: 1$; dan $5: 1$. Kepingan PCB seberat 0,2 g dimasukkan kedalam campuran setelah homogen. Gelas kemudian ditutup rapat dan didiamkan pada suhu kamar selama 0, 1, 3 dan 5 hari. Kepingan PCB kemudian dipisahkan dari larutannya dan dicuci dengan akuades. Larutan hasil pelarutan PCB dianalisis menggunakan SSA untuk mengetahui jumlah tembaga yang berhasil dilarutkan. 


\section{Pelarutan selektif logam tembaga dari kepingan PCB}

Kepingan PCB seberat 0,6 g dimasukkan ke dalam gelas beker berisi $6 \mathrm{~mL}$ campuran $\mathrm{H}_{2} \mathrm{O}_{2} / \mathrm{H}_{2} \mathrm{SO}_{4}$ dengan perbandingan volume yang optimum dari hasil tahap sebelumnya adalah $3: 1$. Gelas kemudian ditutup rapat dan didiamkan pada suhu kamar selama 3 hari. Setelah 3 hari, kepingan PCB dipisahkan dari larutannya dan dicuci dengan akuades. Pengulangan dilakukan sebanyak 3 kali. Larutan hasil pelarutan selektif disisihkan untuk dianalisis menggunakan spektrometer serapan atom (SSA).

\section{PEMBAHASAN}

\section{Kandungan Logam dalam Printed Circuit Board (PCB)}

Wahib et al. (2014) hanya mendapatkan 71,29 g serbuk sampel dari 294,91 g Random Acces Memory (RAM) komputer dengan kadar tembaga sebesar 32,6\%.

Tabel 1. Kandungan logam dalam PCB

\begin{tabular}{cc}
\hline Logam & Kandungan (\%) \\
\hline $\mathrm{Cu}$ & 57,69 \\
$\mathrm{Ba}$ & 17,38 \\
$\mathrm{Sn}$ & 13,43 \\
$\mathrm{Ca}$ & 6,86 \\
$\mathrm{~Pb}$ & 1,13 \\
$\mathrm{Fe}$ & 1,04 \\
$\mathrm{Au}$ & 0,59 \\
$\mathrm{Ni}$ & 0,57 \\
$\mathrm{Cr}$ & 0,23 \\
\hline
\end{tabular}

Potongan PCB yang dianalisis merupakan potongan/bagian yang banyak mengandung logamnya kemudian dianalisis dengan menggunakan $X R F$. Pada bagian yang banyak mengandung logam akan berwarna kecoklatan seperti warna tembaga. Selain itu, banyak timah yang berwarna putih yang melekat pada PCB. Pada bagian yang tidak banyak mengandung logam akan cenderung berwarna hijau. Warna hijau dimungkinkan dari bahan resin organik dan material kaca sebagai bahan dasar PCB. Bagian tersebut merupakan polimer yang digunakan sebagai tempat melekatnya logam. Limbah PCB mengandung sekitar 30\% material logam, 40\% resin berbahan dasar organik dan 30\% material kaca sebagai penguat resin organik (Hino et al., 2009). Kandungan logam dalam PCB disajikan dalam Tabel 1.

Hasil karakterisasi $X R F$ yang dilakukan menunjukkan adanya kandungan tembaga pada sampel PCB yang sangat tinggi, yaitu mencapai 57,69\%. Hasil karakterisasi juga memperlihatkan keberadaan keduanya sebesar 0,57\% (Ni) dan 0,23\% (Cr). 
Nikel dan krom mempunyai potensial reduksi $\left(\varepsilon^{0}\right.$ red $)$ yang lebih kecil daripada tembaga. Potensial reduksi dari nikel, krom dan tembaga adalah sebagai berikut:

$$
\begin{array}{ll}
\mathrm{Cu}^{2+}{ }_{(a q)}+2 e^{-} \rightarrow \mathrm{Cu}_{(s)} & \varepsilon^{0}=+0,342 \text { volt } \\
\mathrm{Ni}^{2+}{ }_{(a q)}+2 e^{-} \rightarrow \mathrm{Ni}_{(s)} & \varepsilon^{0}=-0,257 \text { volt } \\
\mathrm{Cr}^{2+}{ }_{(a q)}+2 e^{-} \rightarrow \mathrm{Cr}_{(s)} & \varepsilon^{0}=+0,170 \text { volt }
\end{array}
$$

Oleh karena itu, nikel dan krom dapat digunakan untuk melapisi tembaga di dalam PCB supaya tidak korosi. Pada prinsipnya, hal ini merupakan proses pengendapan logam secara elektrokimia (perlindungan katodik). Nikel dan krom akan cenderung mengalami oksidasi karena mempunyai potensial reduksi yang lebih kecil dibanding dengan tembaga.

Penggunaan emas dalam komponen PCB dikarenakan logam tersebut mempunyai konduktivitas panas dan listrik, serta ketahanan terhadap oksidasi yang sangat baik (Rasli, 2013). Emas mampu menghantarkan arus listrik yang nyaris tanpa hambatan atau disebut juga dengan zeroresistensi. Konduktivitas panas dan listrik dari logam emas masingmasing adalah $317 \mathrm{~W} / \mathrm{mK}$ dan $48,8 \times 10^{6} \mathrm{ohm}^{-1} \mathrm{~cm}^{-1}$ (Sunardi, 2006). Emas memiliki sifat yang inert atau susah bereaksi dengan senyawa lain. Emas memiliki nilai potensial reduksi sebesar 1,498 V (Sensustania et al., 2013).

\section{Pelarutan selektif logam tembaga dari limbah PCB}

Menurut Mohammed dan Mahdi (2012), logam tembaga yang dapat diekstrak menggunakan PEG sebesar 57,46\%. Oleh karena itu, keberadaan tembaga yang cukup dominan dapat dikurangi atau diambil dari limbah PCB. Pelarutan selektif dapat digunakan sebagai alternatif untuk mengambil kandungan tembaga dari PCB (Kamberovic et al., 2009).

Berdasarkan penelitian ini, logam-logam yang terkandung dalam PCB telah berhasil dipisahkan dengan proses pelarutan selektif. Terlepasnya tembaga dari kepingan PCB diindikasikan dengan munculnya warna biru pada larutannya. Warna biru dari larutan hasil pelarutan selektif diindikasikan sebagai larutan tembaga(II) sulfat (Vogel, 1990). Kepastian adanya tembaga(II) sulfat dalam larutan ditentukan dengan analisis menggunakan SSA. Tembaga yang ada di dalam PCB bereaksi dengan asam sulfat dan menghasilkan tembaga(II) sulfat berdasarkan reaksi berikut:

$$
\mathrm{Cu}_{(s)}+\mathrm{H}_{2} \mathrm{SO}_{4(a q)}+\mathrm{H}_{2} \mathrm{O}_{2(a q)} \rightarrow \mathrm{CuSO}_{4(a q)}+2 \mathrm{H}_{2} \mathrm{O}_{(l)} \text { (Veglio et al., 2006) }
$$

Peran dari hidrogen peroksida sebagai oksidator dalam proses pelarutan tembaga sangat penting. Tanpa adanya hidrogen peroksida, maka tembaga tidak dapat teroksidasi membentuk tembaga(II) yang berwarna biru sehingga larutan tetap tidak berwarna. 
Perpanjangan waktu pelarutan selektif hingga 5 hari pun tetap tidak menunjukkan adanya tembaga yang larut membentuk tembaga(II) sulfat.

Pada hari kelima muncul warna yang berbeda dengan yang lainnya, yaitu pada variasi $1: 1$ dan 2 : 1 . Pada variasi tersebut, larutan berwarna hijau keruh yang mengindikasikan adanya ion $\mathrm{Ni}(\mathrm{II})$ dan $\mathrm{Fe}(\mathrm{II})$ berdasarkan reaksi berikut (Veglio et al., 2006):

$$
\begin{aligned}
& \mathrm{Ni}_{(s)}+\mathrm{H}_{2} \mathrm{SO}_{4(a q)}+\mathrm{H}_{2} \mathrm{O}_{2(a q)} \rightarrow \mathrm{NiSO}_{4(a q)}+2 \mathrm{H}_{2} \mathrm{O}_{(l)} \\
& \mathrm{Fe}_{(s)}+\mathrm{H}_{2} \mathrm{SO}_{4(a q)}+\mathrm{H}_{2} \mathrm{O}_{2(a q)} \rightarrow \mathrm{FeSO}_{4(a q)}+2 \mathrm{H}_{2} \mathrm{O}_{(l)}
\end{aligned}
$$

Keberadaan ion $\mathrm{Ni}(\mathrm{II})$ dan $\mathrm{Fe}(\mathrm{II})$ baru terlihat pada hari kelima yang diindikasikan dengan warna hijau dikarenakan pada hari kelima logam tembaga sudah banyak yang larut. Nikel dan besi juga akan bereaksi dengan asam sulfat ketika konsentrasi tembaga dalam PCB sudah berkurang. Pada awalnya konsentrasi tembaga sangat tinggi sehingga reaksi antara tembaga dengan asam sulfat terjadi dengan cepat (Chang, 2004). Reaksi tersebut berjalan sampai hari ketiga.

Analisis lebih lanjut terhadap larutan hasil pelarutan selektif menggunakan SSA untuk mengetahui konsentrasi tembaga yang terlarut. Berdasarkan Gambar 1 dapat dilihat bahwa kondisi optimum untuk pelarutan selektif tembaga dari PCB menggunakan campuran $\mathrm{H}_{2} \mathrm{O}_{2} 30 \%$ dan $\mathrm{H}_{2} \mathrm{SO}_{4} 4 \mathrm{M}$ dengan perbandingan volume $3: 1$ selama 3 hari. Tembaga yang terlepas pada kondisi tersebut sebanyak 25,415 ppm.

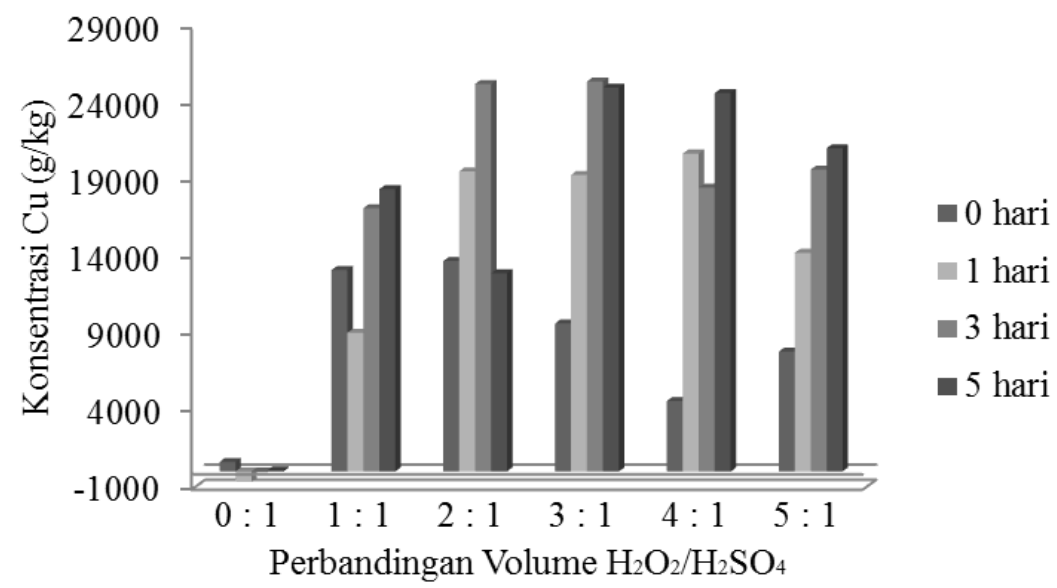

Gambar 1. Konsentrasi tembaga yang terlarut pada proses pelarutan selektif dengan berbagai variasi waktu dan perbandingan volume $\mathrm{H}_{2} \mathrm{O}_{2} / \mathrm{H}_{2} \mathrm{SO}_{4}$.

Pelarutan selektif dilakukan pada temperatur kamar dan tanpa pengadukan karena adanya pengadukan menyebabkan terhambatnya proses pelarutan tembaga. Hal itu dikarenakan hidrogen peroksida dapat terdegradasi yang menghasilkan oksigen. Oksigen tersebut diserap oleh permukaan partikel sehingga kontak antara partikel dengan peroksida 
terhambat. Temperatur yang terlalu tinggi juga dapat menyebabkan degradasi dari hidrogen peroksida (Adebayo et al., 2003).

Anomali data terjadi pada variasi 2: 1 untuk waktu pelarutan selektif 5 hari. Penurunan konsentrasi tembaga terjadi pada variasi tersebut. Hal ini dimungkinkan karena hidrogen peroksida telah mengalami degradasi menjadi oksigen sehingga reaksi antara tembaga dengan asam sulfat terhambat. Tembaga(II) sulfat bereaksi dengan nikel dan besi menurut persamaan reaksi berikut:

$$
\begin{aligned}
& \mathrm{CuSO}_{4(a q)}+\mathrm{Ni}_{(s)} \rightarrow \mathrm{NiSO}_{4(a q)}+\mathrm{Cu}_{(s)} \\
& \mathrm{CuSO}_{4(a q)}+\mathrm{Fe}_{(s)} \rightarrow \mathrm{FeSO}_{4(a q)}+\mathrm{Cu}_{(s)}
\end{aligned}
$$

Reaksi ini terjadi karena tembaga mempunyai potensial reduksi lebih besar dibanding dengan nikel dan besi.

$$
\begin{array}{ll}
\mathrm{Cu}^{2+}{ }_{(a q)}+2 \mathrm{e} \rightarrow \mathrm{Cu}_{(s)} & \mathrm{E}^{0}=+0,34 \text { Volt } \\
\mathrm{Ni}^{2+}{ }_{(a q)}+2 \mathrm{e} \rightarrow \mathrm{Ni}_{(s)} & \mathrm{E}^{0}=-0,26 \text { Volt } \\
\mathrm{Fe}^{2+}{ }_{(a q)}+2 \mathrm{e} \rightarrow \mathrm{Fe}_{(s)} & \mathrm{E}^{0}=-0,44 \text { Volt }
\end{array}
$$

Tembaga akan mengalami reduksi dan mengendap sehingga larutan menjadi keruh. Hal itu dapat dilihat dari hasil analisis menggunakan SSA yang memperlihatkan bahwa konsentrasi tembaga dalam larutan cenderung menurun.

Analisis logam tidak hanya dilakukan pada larutan hasil pelarutan selektif saja, tetapi kepingan PCB setelah proses pelarutan selektif juga dianalisis kembali dengan XRF dengan 3 kali pengulangan untuk mengetahui kadar unsur mana saja yang mengalami perubahan. Data hasil analisis XRF yang diperoleh disajikan pada Tabel 2.

Tabel 2. Kadar logam dalam PCB setelah pelarutan selektif

\begin{tabular}{cc}
\hline Logam & Kandungan $(\%)$ \\
\hline $\mathrm{Cu}$ & 0,00077 \\
$\mathrm{Ba}$ & 0,000109 \\
$\mathrm{Au}$ & 0,2308 \\
$\mathrm{Ni}$ & 0,000033 \\
\hline
\end{tabular}

Berdasarkan data pada Tabel 2, tembaga yang masih tersisa adalah sebesar 7,7 $\mathrm{x}$ $10^{-4} \%$. Sebagian besar tembaga $(99,999 \%)$ berhasil dipisahkan dengan proses pelarutan selektif menggunakan campuran $\mathrm{H}_{2} \mathrm{O}_{2}$ dan $\mathrm{H}_{2} \mathrm{SO}_{4}$ dengan rasio volume 3 : 1 selama 3 hari yang menyebabkan menurunnya persentase tembaga di dalam PCB. Hal tersebut menunjukkan bahwa proses pelarutan selektif dengan menggunakan $\mathrm{H}_{2} \mathrm{O}_{2} / \mathrm{H}_{2} \mathrm{SO}_{4}$ yang dilakukan telah berhasil menurunkan kadar tembaga. Tembaga yang berhasil dilarutkan pada proses pelarutan tembaga ini melebihi proses yang telah dilakukan sebelumnya. 
Birloaga et al. (2013) berhasil melarutkan tembaga dari PCB sebanyak 90\% setelah proses pelarutan selektif kedua.

\section{KESIMPULAN}

Limbah PCB mengandung berbagai macam logam, salah satu diantaranya adalah tembaga. Tembaga dapat dipisahkan terlebih dahulu sebelum dibuang ke lingkungan dengan metode pelarutan selektif. Pelarutan selektif dilakukan dengan menggunakan campuran hidrogen peroksida dan asam sulfat dengan perbandingan $3: 1$ selama 3 hari perendaman. Pelarutan selektif dapat menurunkan kadar tembaga dalam limbah PCB dari $57,7 \%$ menjadi $7,7 \times 10^{-4} \%$. Penurunan kadar tembaga dalam PCB dapat mencapai $99,999 \%$.

\section{DAFTAR PUSTAKA}

Adebayo, A.O., Ipinmoroti, K.O., dan Ajayi, O.O., 2003. Dissolution Kinetics of Chalcopyrite with Hydrogen Peroxide in Sulphuric Acid Medium. Chemical and Biochemical Engineering Quarterly 17 (3), 213-218.

Birloaga, I., Michelis, I.D., Ferella, F., Buzatu, M., dan Veglio, F., 2013. Study on the Influence of Various Factors in the Hydrometallurgical Processing of Waste Printed Circuit Boards for Copper and Gold Recovery. Waste Manage 33, 935-941, DOI: 10.016/j.wasman.2013.01.003.

Castro, L.A., dan Martins, A.H., 2009. Recovery Tin and Copper by Recycling of Printed Circuit Boards from Obsolete Computers. Brazilian Journal of Chemical Engineering 26(6), 649-657.

Chang, R., 2004. Kimia Dasar Jilid 2. edisi ketiga. Erlangga. Jakarta.

Hino, T., Ryuichi, A., Akcil, A., Youichi, M., Minoru, N., Yasuhiro, T., dan Takon, A., 2009. Techniques to Separate Metal from Waste Printed Circuit Boards from Discarded Personal Computers. Journal of Material Cycles and Waste Management $11,42-54$.

Kamberovic, Z., Korac, M., Ivsic, D., Nikolic, V., dan Ranitovic, M., 2009. Hydrometallurgical Process for Extraction of Metals from Electronic Waste-Part I: Material Characterization and Process Option Selection. Association of Metallurgical Engineers of Serbia 15(4), 231-243.

Koyama, K., Tanaka, M., dan Lee, J., 2006. Copper Leaching Behavior from Waste Printed Circuit Board in Ammonical Alkaline Solution. Materials Transactions 47(7) 1788-1792. DOI: $10.2320 /$ matertrans.47.1788.

Mohammed, W.T dan Mahdi, A.S., 2012. Liquid-liquid Extraction of Metal Ions using Aqueous Biphasic Systems. Journal Engineering 18(9), 989-998.

Rasli, R.B., 2013. Limbah Elektronik yang Mempunyai Kandungan Emas. diakses tanggal 2 April 2017 (http://id.scribd.com/) 
Sensustania, H., Tjahjanto, R.T., dan Purwonugroho, D., 2013. Ozonisasi Emas dalam Larutan NaCl. Kimia Student Journal 2(2), 447-481.

Sunardi, 2006. 116 Unsur Kimia Deskripsi dan Pemanfaatannya. Yrama Widya. Bandung.

Veglio, F., Ferella F., De Michelis, L., Furlani, G., Navarra, M., Pagnanelli, F., Toro, L., dan Beolchini, F., 2006. Recovery of Zinc and Manganese from Spent Batteries, Acta Metallurgia Slovaca 12, 95-104.

Vogel, 1990. Buku Teks Analisis Anorganik Kualitatif Makro dan Semimikro. edisi kelima, PT Kalman Media Pustaka. Jakarta.

Wahib, A., Tjahjanto., R.T., dan Purwonugroho, D., 2014. Pengaruh Suhu pada Ekstraksi Emas dari Limbah RAM (Random Acces Memory) Komputer. Kimia Student Journal $1(2), 283-289$. 